Original Article

\title{
DEVELOPMENT OF A SENSOR BY ELECTRO-POLYMERIZATION OF ERICHROME BLACK-T ON GLASSY CARBON ELECTRODE AND DETERMINATION OF AN ANTI-INFLAMMATORY DRUG DICLOFENAC
}

\author{
ROHINI M. HANABARATTI ${ }^{1}$, JAYANT I. GOWDA ${ }^{2}$, SURESH M. TUWAR ${ }^{*}$
}

${ }^{1}$ Department of Chemistry, Karnatak Science College, Dharwad 580001, Karnataka, India, ${ }^{2}$ P. G. Department of Chemistry, P. C. Jabin Science College, Hubballi 580031, Karnataka, India

Email: sm.tuwar@gmail.com

Received: 04 Nov 2018 Revised and Accepted: 31 Dec 2018

\section{ABSTRACT}

Objective: The aim of this study was to develop a simple, reliable voltammetric method and its validation for determination of nonsteroidal antiinflammatory drug diclofenac (DFC).

Methods: The proposed method was based on electro-oxidation of DFC at poly (erichrome black T) modified glassy carbon electrode (PEBT/GCE) in $0.2 \mathrm{M}$ phosphate buffer solution of $\mathrm{pH}$ 7.0. Cyclic voltammetry and differential pulse voltammetric techniques were employed to study electrooxidation behavior. Under the optimal conditions, variations of EBT concentration, effect of pH, scan rate on the oxidation of DFC was studied.

Results: A well-defined oxidation peak at about $+0.59 \mathrm{~V}$ vs. standard calomel electrode was observed for voltammetric detection of DFC. pH effect shows the participation of an equal number of protons and electrons in the mechanism. The relation between a logarithm of peak current with the logarithm of scan rate indicated adsorption controlled behavior of electrode process. Concentration variations show a good linear response in the range $0.05 \mu \mathrm{M}$ to $40 \mu \mathrm{M}$ with the detection limit of $5.25 \times 10^{-8} \mathrm{M}$.

Conclusion: The prepared sensor exhibited good selectivity, sensitivity, and stability for the detection of DFC in the pharmaceutical dosage form and real samples. The developed method could possibly be adopted for pharmacokinetic studies and also in clinical and quality control laboratories where time and economy were important.

Keywords: Diclofenac, Modified electrode, Detection limit, Calibration plot

(C) 2019 The Authors. Published by Innovare Academic Sciences Pvt Ltd. This is an open-access article under the CC BY license (http://creativecommons.org/licenses/by/4.0/) DOI: http://dx.doi.org/10.22159/ijpps.2019v11i2.30648

\section{INTRODUCTION}

Diclofenac (2-(2-(2,6-dichlorophenylamino)phenyl)acetic acid), as shown in (fig. 1) is a non-steroidal anti-inflammatory drug. It is widely used as an analgesic, anti-rheumatic, anti-inflammatory, antithermal and for the treatment of arthritis and degenerative joint disease $[1,2]$. These drugs are applied both for acute and long-term chronic cases [3]. Clinically, the sodium salt of diclofenac is the most generally used painkiller [4]. Patients are frequently given special formulations of DFC or a co-treatment agent as a therapeutic strategy to attenuate the gastrointestinal tract complications that limit the use of DFC and other NSAIDs [5-7].

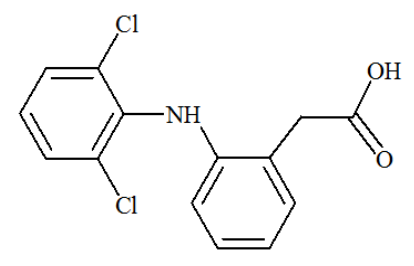

Fig. 1: Chemical structure of DFC

Drug analysis is an important branch of analytical chemistry and plays an important role in drug quality control. Electro-analytical techniques have been used for the determination of a wide range of drug compounds. Numerous analytical methods have been reported for the determination of DFC [8-24]. Compared to voltammetric methods, most of the methods reported in the literature are costly, need complex pre-concentration as well as derivatization. Many methods require expensive instruments, long analysis time, a highly skilled technician and laborious sample pretreatment, which make them unsuitable for routine analysis. Taking the above-mentioned lacune, electrochemical methods are characterized by portability, simplicity, minimal cost, and reasonably short analysis time.

DFC shows the low current response at the bare electrodes. This problem can be solved through modification of electrodes. Chemical modification such as nanoparticle composite electrodes and polymer modified electrodes have attracted great attention as they have good stability and reproducibility for sensitive determination of pharmaceutical drugs [25-26]. Electro-polymerization is a good approach to immobilize polymers because adjusting the electrochemical parameters can control film thickness, permeation and charge transport characteristics [27-33]. Poly (eriochrome black T) modified glassy carbon electrode [34-37] have attracted more attention because of their novel electrode material which exhibits several excellent electrochemical properties and high electrochemical stability.

To the best of our knowledge, very little work has been reported on the electrochemical determination of DFC. In this work, the electrocatalytic activity of a PEBT/GCE was investigated for the electrochemical oxidation of DFC in buffer solution using cyclic voltammetry. The objective of the current work was to develop a simple and sensitive method for the determination of DFC, based on the excellent electrochemical properties and high electrochemical stability of EBT.

\section{MATERIALS AND METHODS}

Experimental

Apparatus

Electrochemical experiments were carried out on Model CHI1112C (Version 9.03) USA with a traditional three electrode compartment. A calomel electrode, a platinum wire, and a PEBT/GCE were used as 
the reference, auxiliary and working electrodes, respectively. Elico $\mathrm{pH}$ meter was used for $\mathrm{pH}$ measurements.

\section{Preparation of the poly (EBT)-modified electrode}

Prior to the modification, for good reproducible results and to improve sensitivity and resolution of voltammetric peaks, GCE was polished with $1 \mu \mathrm{m}, 0.3 \mu \mathrm{m}$ and $0.05 \mu \mathrm{m} \alpha$-alumina powder, and then washed successively with doubly distilled water in an ultrasonic bath, and allowed to dry at room temperature. Later, the PEBT/GCE was prepared by electropolymerization of GCE in $0.5 \mathrm{M} \mathrm{H}_{2} \mathrm{SO}_{4}$ containing different concentrations of EBT. Best results were obtained for 1.0 mmol EBT within the potential series of $-0.4 \mathrm{~V}$ to $1.5 \mathrm{~V}$ for 20 cycles with the scan rate of $0.025 \mathrm{Vs}^{-1}$. The surface area of the modified electrode was evaluated and compared with the bare electrode.

\section{Analytical procedure}

The PEBT/GCE was first stabilized in $10 \mathrm{ml} 0.2 \mathrm{M}$ phosphate buffer solution ( $\mathrm{pH}$ 7.0) by 3 cyclic voltammetric (DPV) sweeps between 0.0 $\mathrm{V}$ to $1.4 \mathrm{~V}$. Then, the electrode was transferred into another glass conventional cell containing an adequate amount of $0.2 \mathrm{M}$ phosphate buffer solution ( $\mathrm{pH} 7.0$ ), and aliquots of the stock solution of DFC were added.

The DFC determinations in pharmaceutical and urine samples were carried out by differential pulse voltammetry. A systematic study of DPV parameters was conducted, and the best chemical conditions were initially evaluated. After optimization of the parameters, the DPV voltammograms were obtained in a potential range from $+0.3 \mathrm{~V}$ to $+0.8 \mathrm{~V}$ vs. $\mathrm{Ag} / \mathrm{AgCl}\left(3.0 \mathrm{~mol} \mathrm{~L}^{-1} \mathrm{KCl}\right)$ with an accumulation time of 60 s. The analytical curve was constructed using the DPV voltammograms obtained after the successive addition of aliquots of the DFC stock solution into the electrochemical cell containing an appropriate amount of $0.2 \mathrm{M}$ phosphate buffer solution ( $\mathrm{pH} 7.0$ ). Each concentration was a measurement in triplicate.

\section{Pharmaceutical sample preparation}

Commercial samples (50 mg DFC tablets) were obtained from a local market. Ten DFC tablets were weighed and ground to a homogeneous powder in a mortar and then placed into a $250 \mathrm{ml}$ of conical flask. Little warm water was added into the flask and the sample was sonicated for $30 \mathrm{~min}$ to dissolve completely and left to cool. The sample solution was filtered through a filter paper (Whatman No. 42) into $100 \mathrm{ml}$ volumetric flask and made up to the volume with $0.2 \mathrm{M}$ phosphate buffer $\mathrm{pH}$ 7.0.

\section{Urine sample preparation}

The fresh human urine samples were collected in dark glass containers, filtered through Whatman 42 filter paper, stored in a refrigerator and analyzed within $8 \mathrm{~h}$ after collection. Without any pre-treatment, samples were diluted with the buffer solution of $\mathrm{pH}$ 7.0 to the working range of the determination of DFC, and then it was used for analysis. The standard addition method was used for the determination of an analyte in real samples.

\section{RESULTS AND DISCUSSION}

\section{Electrocatalytic oxidation of DFC at poly (eriochrome black T) modified GCE}

The electrochemical behavior of DFC was studied by cyclic voltammetry in a $0.2 \mathrm{~mol} \mathrm{~L}^{-1}$ phosphate buffer solution ( $\mathrm{pH}$ 7.0). The cyclic voltammogram obtained for a $1.0 \times 10^{-4} \mathrm{~mol} \mathrm{~L}^{-1} \mathrm{DFC}$ solution using the PEBT/GCE was compared with the cyclic voltammograms of GCE (fig. 2). In the bare GCE, a low oxidation peak was observed at $+0.62 \mathrm{~V}$. Under identical experimental conditions, a higher anodic peak current density was observed for PEBT/GCE at $+0.59 \mathrm{~V}$. This result is clear evidence of catalytic behavior of developed electrode towards DFC. The cyclic voltammograms presented an anodic peak due to the oxidation of DFC and no peak in the reverse direction was observed, indicating that the oxidation of DFC on the electrodes is an irreversible process.

Effect of supporting electrolyte and solution $\mathrm{pH}$
The voltammetric behavior of DFC was investigated by cyclic voltammetry in many supporting electrolytes, such as sulfuric acid, phosphate buffer, acetate buffer, Britton-Robinson buffer, and $\mathrm{KCl}$ solutions. The best anodic peak with regard to the definition and smaller potential work for DFC oxidation was obtained in phosphate buffer solution. After this study, the effect of solution $\mathrm{pH}$ on the oxidation of DFC at the PEBT/GCE was investigated in a $0.2 \mathrm{~mol} \mathrm{~L}^{-1}$ phosphate buffer solution over the $\mathrm{pH}$ range from 3.0 to 9.2. Cyclic voltammograms of $1.0 \times 10^{-4} \mathrm{~mol} \mathrm{~L}^{-1}$ DFC (scan rate $50 \mathrm{mV} \mathrm{s}^{-1}$ ) were recorded (fig. $3 \mathrm{~A}$ ). It has been noticed that the anodic peak potentials shifted to less positive potentials when the $\mathrm{pH}$ increases as shown in fig. 3B with regression equation $\mathrm{E}_{\mathrm{pa}}=-0.0539 \mathrm{mV} / \mathrm{pH}+0.8346$, $\mathrm{R}^{2}=0.9813$. In addition, the analytical signal gradually increased from pH 3.0 to 7.0 and the highest value was observed at pH 7.0 (fig. 3C). Thus, a pH 7.0 (0.2 mol L-1 phosphate buffer solution) was selected as supporting electrolyte for further study.

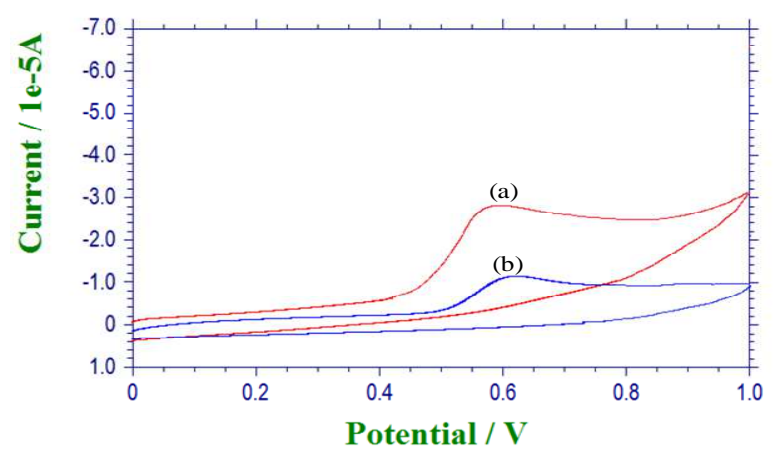

Fig. 2: Cyclic voltammograms of $0.1 \mathrm{mmol}$ DFC at poly (EBT) modified glassy carbon electrode in $0.2 \mathrm{M}$ phosphate buffer solution of $\mathrm{pH} 7.0$ with scan rate $0.05 \mathrm{~V} / \mathrm{s}$. a) PEBT/GCE b) bare GCE

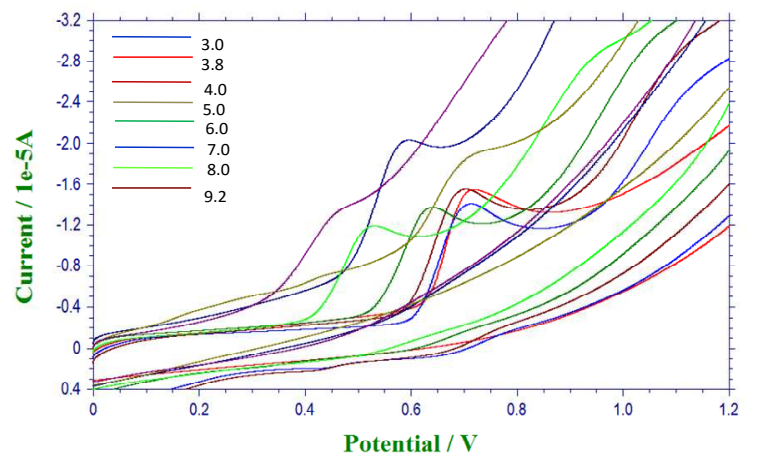

Fig. 3A: The effect of phosphate buffer $\mathrm{pH}$ on the peak current of $0.1 \mathrm{mmol}$ DFC at $\mathrm{pH}$ : 3.0-9.2. Scan rate $50 \mathrm{mV} \mathrm{s}^{-1}$

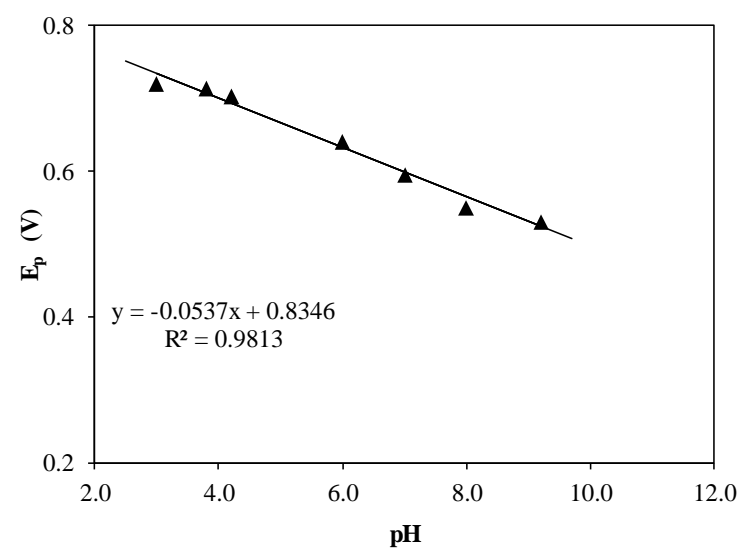


Fig. 3B: The relationship between the peak potential and $\mathrm{pH}$ at 50 mVs $^{-1}$ using PEBT/GCE

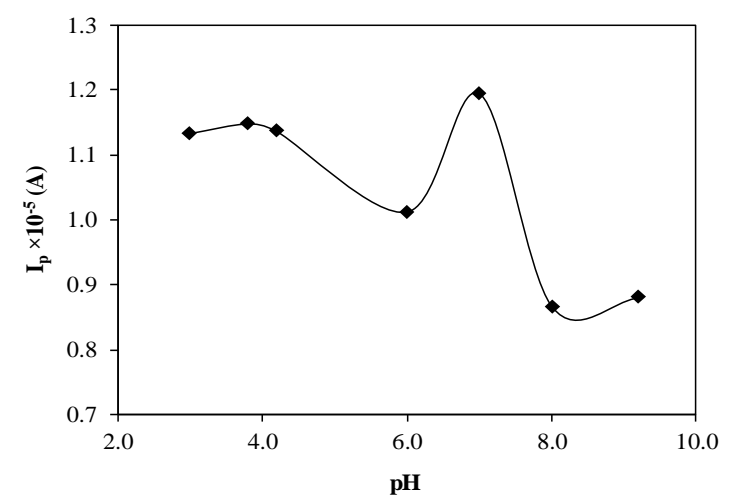

Fig. 3C: Relationship between the oxidation peak current and the $\mathrm{pH}$

\section{Effect of accumulation potential and adsorption time}

The effect of accumulation potential on the oxidation of $1.0 \times 10^{-4} \mathrm{M}$ DFC was investigated on the PEBT/GCE. The range of potential evaluated was from 0.0 to $1.4 \mathrm{~V}$, and the obtained peak current density was constant in this potential range, suggesting that the accumulation potential had no effect on the oxidation peak current density. Thus, an open-circuit accumulation of analyte was adopted. The influence of the accumulation time on the oxidation peak current density of DFC was also studied (fig. 4). The anodic peak increases with the accumulation time from 0 to $60 \mathrm{~s}$. After this time, it remained practically constant due to saturation of the electrode surface. Therefore, an accumulation time of $60 \mathrm{~s}$ was selected for further work.

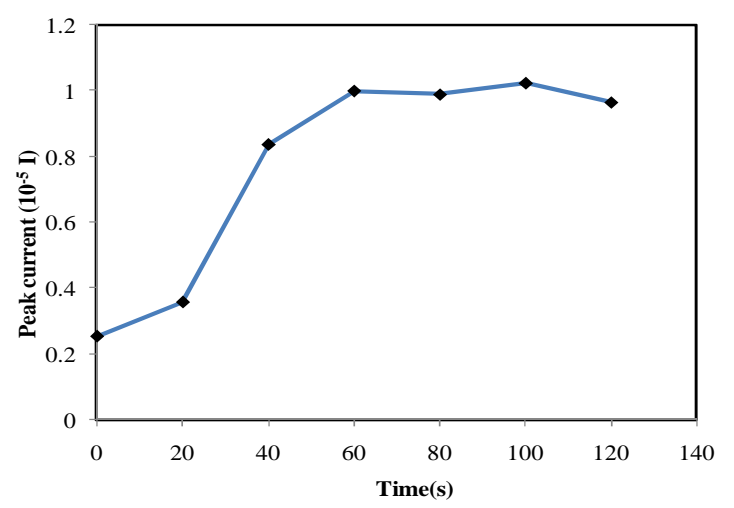

Fig. 4: Effect of accumulation time on peak current of $0.1 \mathrm{mmol}$ DFC

\section{The effect of scan rate}

The electrochemical response of $0.1 \mathrm{mmol}$ DFC at PEBT/GCE was investigated at different scan rates from $50-250 \mathrm{mVs}^{-1}$. The PEBT/GCE showed an increase in the peak currents with the increase in the scan rates with a small shift in the oxidation peak potential towards more positive potential. This result is in accordance with Randles-Sevick's equation, confirming the kinetic limitation of the electrochemical process. The plot of anodic peak current $\left(I_{p}\right)$ versus scan rate $(\mathrm{v})$ gives almost straight line (fig. $5 \mathrm{~A}$ ) with linear regression equation of $\operatorname{Ip}(\mu \mathrm{A})=0.915 v(\mathrm{mVs}-1)+1.9089$; $\mathrm{R}^{2}=0.9926$. The plot of log peak current vs log scan rate shows a linear relationship with the slope value of 0.784 , which is nearly equal to 1.0 , indicates that the electrode process was controlled predominantly by adsorption process rather than diffusion process in the investigated scan rates [38]. With an increase of $v$, the peak potential $\left(E_{\mathrm{pa}}\right)$ shifts positively and there is a linear relationship between them, the regression equation is: Epa $=0.038 \log v+0.523$; ( $E_{p a}$ in $\mathrm{V}, v$ in $\mathrm{Vs}^{-1}, \mathrm{R}^{2}=0.980$, fig. $5 \mathrm{~B}$ ). For irreversible electrode process, Leviron equation was used to calculate the number of electrons transferred and heterogeneous rate constant [39]:

$$
\mathrm{E}_{\mathrm{pa}}=\mathrm{E}^{0^{\prime}}+\left(\frac{2.303 \mathrm{RT}}{\alpha \mathrm{nF}}\right) \log \left(\frac{\mathrm{RTk}^{0}}{\alpha \mathrm{nF}}\right)+\left(\frac{2.303 \mathrm{RT}}{\alpha \mathrm{nF}}\right) \log v
$$

Value of $\alpha$ was calculated by the following equation as given by Bard and Faulkner [40],

$$
\alpha=\frac{47.7}{E_{p}-E_{p / 2}} \mathrm{mV}
$$

Here $E_{\mathrm{P} / 2}$ is the potential when the current is at half the peak value. From this, the value of $\alpha$ was calculated to be 0.7014 . The $\alpha \mathrm{n}$ is calculated to be 1.556 hence $n$ is equal to 2.21 . Other symbols are having their usual meanings. Further, the heterogeneous rate constant $\mathrm{k}^{\circ}$ was calculated from the intercept of the log scan rate vs. $E_{p a}$ if the value of $E^{\circ}$ is known. The value of $E^{\circ}$ in above can be obtained from the intercept of $\mathrm{E}_{\mathrm{pa}} \mathrm{vs}$. $v$ curve by extrapolating to the vertical axis at $v=0$ [41]. In our system the intercept for $E_{\mathrm{pa}} \mathrm{vs.} \log v$ plot was 0.523 and $\mathrm{E}^{\circ}$ was obtained to be 0.514 and the $\mathrm{k}^{\circ}$ was calculated to be $104.84 \mathrm{~s}^{-1}$.

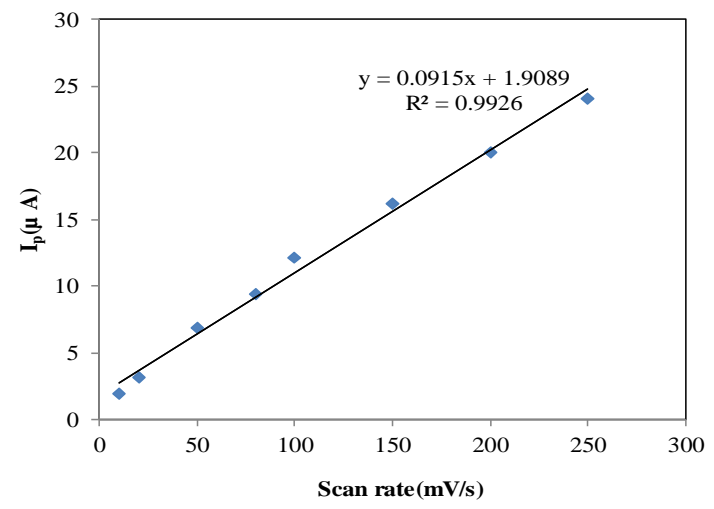

Fig. 5A: Dependence of peak current on scan rate for $0.1 \mathrm{mmol}$ DFC

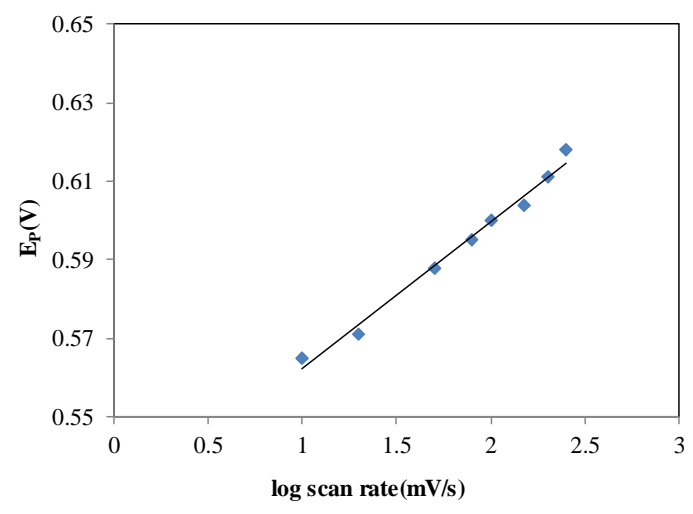

Fig. 5B: Plot of variation of peak potential $\left(E_{p} / V\right)$ with logarithm of scan rate $\left(\log v / \mathrm{mVs}^{-1}\right)$

\section{Mechanism}

Oxidation of DFC takes place at the positive potential, which depends on $\mathrm{pH}$ and the type of the electrode used. $\mathrm{pH}$ effects show oxidation potential is $\mathrm{pH}$ dependent with a slope of $-0.0539 \mathrm{mV} / \mathrm{pH}$ which was equal to the expected Nernst value for a two-electron, 
two-proton electrochemical reaction. The number of electrons calculated was 2.0. Based on the experimental observations and earlier reported results [15, 42-44], electro-oxidation of diclofenac leads to $5-\mathrm{OH}$ diclofenac as shown in scheme 1.

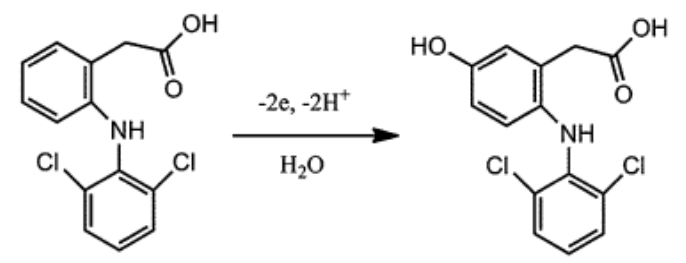

Scheme 1: Electro-oxidation of DFC at PEBT/GCE

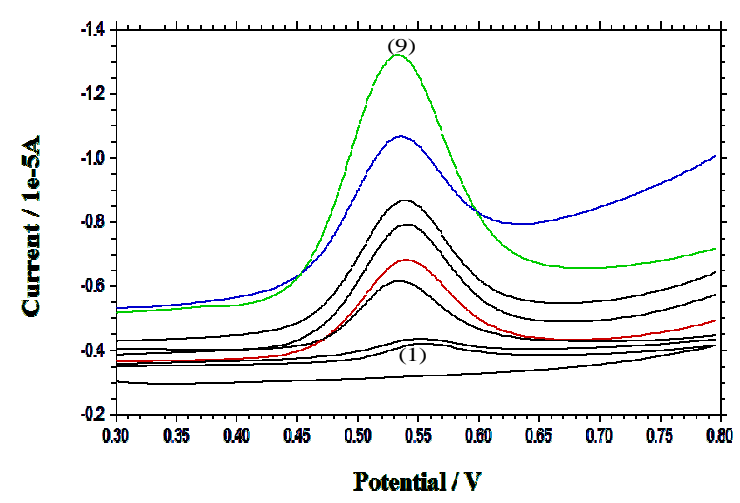

Fig. 6A: Differential pulse voltammograms with increasing concentration of DFC (1-9: 0.05-40 $\mu \mathrm{M})$

\section{The effect of concentration on PEBT/GCE}

The effect of varying concentration of DFC was studied at PEBT/GCE in $0.2 \mathrm{M}$ PBS $\mathrm{H} 7.0$ at a scan rate of $50 \mathrm{mVs}^{-1}$ as shown in the fig. $6 \mathrm{~A}$.
It is clearly observed that anodic peak current of DFC was increased as the concentration of DFC increases in the range $0.05 \times 10^{-6}$ to $40 \times$ $10^{-6} \mathrm{M}$. The plot of $\mathrm{I}_{\mathrm{p}}$ versus concentration of DFC shows linearity in the graph (fig 6B). The linear equation was $\mathrm{I}_{\mathrm{p}}(\mu \mathrm{A})=0.24029$ $\left(\mathrm{DFC} \times 10^{-6} \mathrm{M} / \mathrm{l}\right)+1.087$. The limit of detection and limit of quantification was calculated by using equation (1) and (2).

$$
\begin{gathered}
\mathrm{LOD}=3 \mathrm{~S} / \mathrm{M} \ldots . .(1) \\
\mathrm{LOQ}=10 \mathrm{~S} / \mathrm{M} \ldots . .(2)
\end{gathered}
$$

Where $\mathrm{S}$ is the standard deviation and $\mathrm{M}$ is the slope of calibration plot. The limit of detection and limit of quantification for DFC was found to be $5.25 \times 10^{-8} \mathrm{~mol} \mathrm{~L}^{-1}$ and $1.71 \times 10^{-7} \mathrm{~mol} \mathrm{~L}^{-1}$ respectively. The characteristics of the calibration plot are as given in table 1 . The linear range and detection limit of proposed sensor was compared with some of the earlier reported sensors as shown in table 2.

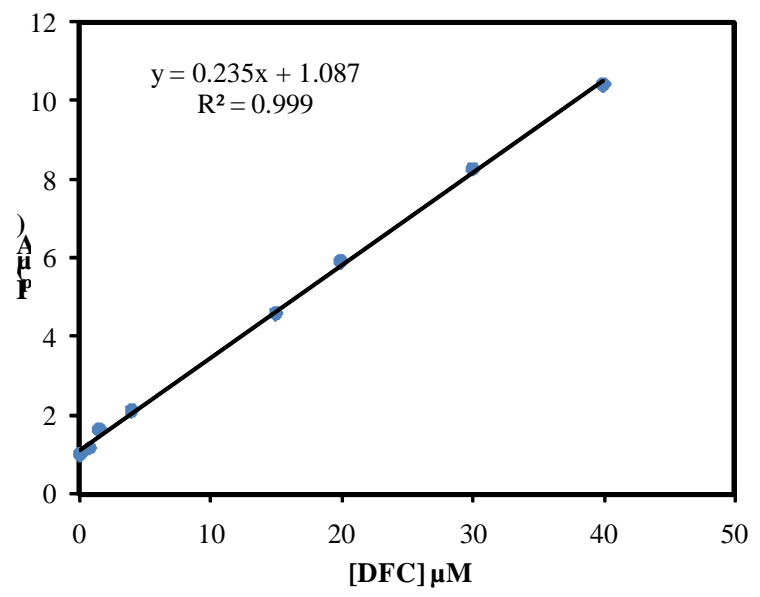

Fig. 6B: Calibration plot showing a linear variation of peak current

Table 1: Regression data of the calibration lines for quantitative determination of diclofenac

\begin{tabular}{ll}
\hline Parameters & DPV \\
\hline Measured potential $(\mathrm{V})$ & $0.3-0.8$ \\
Linearity $(\mu \mathrm{M})$ & $0.05-40$ \\
Slope & 0.2356 \\
Intercept & 1.08 \\
$\mathrm{R}^{2}$ & 0.999 \\
$\mathrm{LOD}(\mu \mathrm{M})$ & 0.0525 \\
$\mathrm{LOQ}(\mu \mathrm{M})$ & 0.175 \\
Repeatability of peak current (RSD\%) & 1.78 \\
Repeatability of peak potential (RSD\%) & 1.61 \\
Reproducibility of peak current (RSD\%) & 4.31 \\
Reproducibility of peak potential (RSD\%) & 4.91 \\
\hline
\end{tabular}

Table 2: Comparison of the analytical parameters of several modified electrodes for diclofenac determination

\begin{tabular}{lll}
\hline Electrode & Linear range & LOD \\
\hline Tyrosine modified carbon paste electrode & $10 \mu \mathrm{M}-140 \mu \mathrm{M}$ & $3.28 \mu \mathrm{M}$ \\
Ionic liquid multiwall carbon nanotubes paste electrode & $0.3 \mu \mathrm{M}-750 \mu \mathrm{M}$ & $0.09 \mu \mathrm{M}$ \\
Ionic liquid-modified carbon nanotubes paste electrode & $0.5 \mu \mathrm{M}-300 \mu \mathrm{M}$ & $0.2 \mu \mathrm{M}$ \\
Multi-Walled Carbon Nanotube-Ionic Liquid Composite Modified Carbon & $50 \mathrm{nM}-20 \mu \mathrm{M}$ & $27 \mathrm{nM}$ \\
Ceramic Electrode & & \\
Cu-Doped Zeolite-Expanded Graphite-Epoxy Electrode & $0.2 \mu \mathrm{M}-30 \mu \mathrm{M}$ & $5 \times 10^{-8} \mathrm{M}$ \\
Carbon Nanotube-Graphite Mixture & $0.15 \mu \mathrm{M}-6.7 \mu \mathrm{M}$ & $5.06 \times 10^{-8} \mathrm{M}$ \\
Silica Nanoparticles Modified Carbon Paste Electrode & $0.1 \mu \mathrm{M}-500.0 \mu \mathrm{M}$ & $0.046 \mu \mathrm{M}$ \\
Immobilized copper ions on MWCNTS-Chitosan modified GCE & $0.3 \mathrm{mmol}-200 \mathrm{mmol}$ & $0.021 \mathrm{mmol}$ \\
Poly(EBT) modified GCE & $0.05 \mu \mathrm{M}-40 \mu \mathrm{M}$ & 46 \\
\hline
\end{tabular}

\section{Reproducibility and stability}

The prepared sensor should exhibit regeneration and reproducibility to get more accurate results. These two properties are important for the prepared sensor. The reproducibility of the sensor was monitored by four parallel electrochemical measurements for $1.0 \times 10^{-6} \mathrm{~mol} \mathrm{~L}^{-1} \mathrm{DFC}$ and the results showed that a relative standard deviation (RSD) of $5.2 \% \quad(n=4)$ was estimated, 
exhibiting a high reproducibility of the constructed sensor. To evaluate the stability of the PEBT/GCE, electropolymerized GCE was kept undisturbed in an elevated condition for one week. No obvious changes were found in the current response to the same sample concentration.

Therefore, the stability of the proposed electrode was good enough for the electrochemical application.

\section{Selectivity}

Selectivity of the method was tested by adding an excess of interfering substances into the detecting system, containing a fixed concentration of the analyte. No remarkable change in the potential was observed by the addition of 100 fold excess of ascorbic acid, dextrose, lactose, urea, lactose, oxalic acid, fructose indicates the good selectivity of the prepared sensor. The results are tabulated in table 3.

Table 3: Influence of potential excipients on the oxidation potential of DFC

\begin{tabular}{lll}
\hline Excipients(1.0 mmol)+ drug (1.0 $\left.\mathbf{1 0} \mathbf{1 0}^{-6}\right)$ & Potential observed (V) & Signal change (\%) \\
\hline Only DFC & 0.596 & - \\
Glucose & 0.574 & -3.69 \\
Gum Acacia & 0.621 & 4.19 \\
Sucrose & 0.576 & -3.35 \\
Citric acid & 0.605 & 1.51 \\
Dextrose & 0.582 & -2.34 \\
Lactose & 0.598 & 0.33 \\
Tartaric acid & 0.584 & -2.01 \\
Starch & 0.582 & -2.43 \\
\hline
\end{tabular}

\section{Analytical application}

\section{Determination of DFC in pharmaceutical dosages}

DPV technique was employed to the direct determination of DFC in tablet dosage forms, using the related calibration curve after adequate dilutions. The results show that the proposed methods were successfully applied for the assay of DFC in its pharmaceutical dosage forms (table 4).

\section{Determination of DFC in spiked urine samples}

The measurement of DFC in urine sample was performed as discussed in the experimental section. The applicability of the proposed methods to the human urine sample, the calibration graph was used. Analysis of drugs from biological samples usually requires extensive time-consuming sample preparation, use of expensive organic solvents and in sometimes, use of other chemicals. In this study, the urine samples were collected in a dark container, and diluted with the supporting electrolyte and directly analyzed. It has been found that using the proposed technique, no sample pretreatment was required, other than dilution step. No oxidation compounds and no extra noise peaks present in biological material peak occurred in the potential range where the analytical peak appeared. The recovery results are as shown in table 5 .

Table 4: Recovery of DFC in pharmaceutical preparations

\begin{tabular}{ll}
\hline Diclofenac & DPV \\
\hline Labeled claim (mg) & 50 \\
Amount found (mg) ${ }^{\mathrm{a}}$ & 48.48 \\
R. SD (\%) & 2.67 \\
Added (mg) & 2.0 \\
Found (mg) & 1.92 \\
Recovered (\%) & 96.37 \\
R. SD of recovery (\%) & 1.49 \\
\hline
\end{tabular}

Table 5: Recovery of DFC in spiked human urine samples

\begin{tabular}{|c|c|c|c|c|}
\hline Sample & Added $\left(\times 10^{6} \mathrm{M}\right)$ & Found $\left(\right.$ mean $\left.\pm S^{a}\right)\left(\times 10^{6} M\right)$ & Recovery (\%) & $\operatorname{RSD}^{\mathrm{b}}(\%)$ \\
\hline 1 & 2 & $2.03 \pm 0.044$ & 101.56 & 2.14 \\
\hline 2 & 4 & $3.99 \pm 0.061$ & 99.87 & 1.55 \\
\hline 3 & 6 & $5.87 \pm 0.160$ & 97.82 & 2.72 \\
\hline 4 & 8 & $8.02 \pm 0.063$ & 100.23 & 0.79 \\
\hline 5 & 10 & $10.15 \pm 0.145$ & 101.46 & 1.43 \\
\hline
\end{tabular}

SDa: Standard deviation of five replicate determinations, RSD: Relative standard deviation, bैAverage of five replicate determinations

\section{CONCLUSION}

The present work illustrates the oxidation behavior of DFC on the poly (erichrome black T) modified glassy carbon electrode. When the potential was made to move, DFC produced one anodic peak at $\sim 0.59$ $\mathrm{V}$ in $0.2 \mathrm{~mol} \mathrm{~L}^{-1}$ phosphate buffer solution ( $\mathrm{pH} \mathrm{7.0).} \mathrm{The} \mathrm{oxidation}$ process was irreversible and adsorption controlled. This method could be used successfully to determine DFC in the pharmaceutical samples. The proposed method offers the advantages of accuracy, as well as the simplicity of reagents and apparatus. In addition, the analysis of DFC present in spiked urine samples demonstrated the applicability of the method for real sample analysis. Furthermore, the present method could possibly be adopted for pharmacokinetic as well as clinical and quality-control laboratories.

\section{AUTHORS CONTRIBUTIONS}

All authors equally contributed

\section{CONFLICT OF INTERESTS}

The authors have no conflict of interest in publication of this article

\section{REFERENCES}

1. Iliescu T, Baia M, Miclaus V. A Raman spectroscopic study of the diclofenac sodium b-cyclodextrin interaction. Eur J Pharm Sci 2004;22:487-95.

2. Tuncay M, Calis S, Kas HS, Ercan MT, Peksoy I, Hincal AA. Diclofenac sodium incorporated PLGA (50:50) microspheres: formulation 
considerations and in vitro/in vivo evaluation. Int J Pharm 200;195:179-88.

3. Nuhu AA, Sallau MS, Bala T. Fixed sized simplex optimization of the spectrophotometric method for the quantitative determination of diclofenac in pharmecutical preparations. Int J Adv Res 2015;3:234-45.

4. Mazumdar K, Dutta NK, Dastidar SG, Motohashi N, Shirataki Y. Diclofenac in the management of E. coli urinary tract infections. In Vivo 2006;20:613-9.

5. Davies NM, Saleh JY, Skjodt NM. Detection and prevention of NSAID-induced enteropathy. J Pharm Pharm Sci 2000;3:137-55.

6. Fortun PJ, Hawkey CJ. Nonsteroidal anti-inflammatory drugs and the small intestine. Curr Opin Gastroenterol 2005;21:169-75.

7. Ciltas U, Yilmaz B, Kaban S, Bilge KA, Gulsah N. Square wave voltammetric determination of diclofenac in pharmaceutical preparations and human serum. Iran J Pharm Res 2015;14:715-22.

8. Shamsipur M, Jalali F, Ershad S. Preparation of a diclofenac potentiometric sensor and its application to pharmaceutical analysis and to drug recovery from biological fluids. J Pharm Biomed Anal 2005;37:943-7.

9. Gonzalez L, Yuln G, Volonte MG. Determination of cyanocobalamin, betamethasone, and diclofenac sodium in pharmaceutical formulations, by high-performance liquid chromatography. J Pharm Biomed Anal 1999;20:487-92.

10. Jin $\mathrm{W}$, Zhang J. Determination of diclofenac sodium by capillary zone electrophoresis with electrochemical detection. J Chromatogr A 2000;868:101-7.

11. Sun SW, Fabre H. Practical approach for validating the TLC assay of an active ingredient in a pharmaceutical formulation. J Liq Chromatogr 1994;17:433-45.

12. Arancibia JA, Boldrini MA, Escandar GM. Spectrofluorimetric determination of diclofenac in the presence of $\alpha$-cyclodextrin. Talanta 2000;52:261-8.

13. Sioufi A, Pommier F, Godbillon J. Determination of diclofenac in plasma and urine by capillary gas chromatography-mass spectrometry with possible simultaneous determination of deuterium-labelled diclofenac. J Chromatogr B 1991;571:87-100.

14. Daneshgar P, Norouzi P, Ganjali MR, Dinarvand R, Moosavi Movahedi AA. Determination of diclofenac on a dysprosium nanowire-modified carbon paste electrode accomplished in a flow injection system by advanced filtering. Sensors 2009;9:7903-18.

15. Goyal RN, Chatterjee S, Singh Rana AR. The effect of modifying an edge-plane pyrolytic graphite electrode with single-wall carbon nanotubes on its use for sensing diclofenac. Carbon 2010;48:4136-44.

16. Goyal RN, Sanghamitra C, Bharati A. Electrochemical investigations of diclofenac at edge plane pyrolytic graphite electrode and its determination in human urine. Sens Actuators B 2010;145:743-8.

17. Arvand M, Gholizadeh TM, Zanjanchi MA. MWCNTs/Cu(OH $)_{2}$ nanoparticles/IL nanocomposite modified glassy carbon electrode as a voltammetric sensor for determination of the non-steroidal anti-inflammatory drug diclofenac. Mat Sci Eng C 2012;32:1682-9.

18. Chethana BK, Basavanna S, Arthoba YN. Voltammetric determination of diclofenac sodium using tyrosine-modified carbon paste electrode. Ind Eng Chem Res 2012;51:1028795.

19. Sarhangzadeh K, Khatami AA, Jabbari M, Bahari S. Simultaneous determination of diclofenac and indomethacin using a sensitive electrochemical sensor based on multiwalled carbon nanotube and ionic liquid nanocomposite. J Appl Electrochem 2013;43:1217-24.

20. Razmi H, Sarhang Zadeh K, Mohammad Rezaei R. Electrochemical behavior and voltammetric determination of diclofenac at a multi-walled carbon nanotube-ionic liquid composite modified carbon ceramic electrode. Anal Lett 2013;46:1885-96.

21. Ensafi AA, Maedeh I, Karimi Maleh H. Sensitive voltammetric determination of diclofenac using room-temperature ionic liquid-modified carbon nanotubes paste electrode. Ionics 2013;19:137-44.
22. Wei L, Borowiec J, Zhu L, Zhang J. Electrochemical investigation on the interaction of diclofenac with DNA and its application to the construction of a graphene-based biosensor. J Solid State Electrochem 2012;16:3817-23.

23. Abdolmajid BM, Ali M, Mozhgan F. Application of carbon nanotube-graphite mixture for the determination of diclofenac sodium in pharmaceutical and biological samples. Pharm Anal Acta 2012;3:1-6.

24. Botello JC, Perez Caballero G. Spectrophotometric determination of diclofenac sodium with methylene blue. Talanta 1995;42:105-8.

25. Brett CMA, Inzelt G, Kertesz V. Poly (methylene blue) modified electrode sensor for haemoglobin. Anal Chim Acta 1999;385:119-23.

26. Zhao H, Zhang Y, Yuan Z. Determination of dopamine in the presence of ascorbic acid using poly (hippuric acid) modified glassy carbon electrode. Electroanal 2002;14:1031-4.

27. Zhang Y, Jin G, Wang Y, Yang Z. Determination of dopamine in the presence of ascorbic acid using poly (Acridine red) modified glassy carbon electrode. Sensors 2003;3:443-50.

28. Manjunatha JG, Deraman M, Basri NH. Electrocatalytic detection of dopamine and uric acid at poly (basic blue b) modified carbon nanotube paste electrode. Asian J Pharm Clin Res 2015;8:40-5.

29. Roy PR, Okajima T, Ohsaka T. Simultaneous electroanalysis of dopamine and ascorbic acid using poly (N, N-dimethylaniline)modified electrodes. Bioelectrochem 2003;59:11-9.

30. Zhang Y, Cai Y, Su S. Determination of dopamine in the presence of ascorbic acid by poly (styrene sulfonic acid) sodium salt/single-wall carbon nanotube film modified glassy carbon electrode. Anal Biochem 2006;350:285-91.

31. Xu F, Gao M, Wang L, Shi G, Zhang W, Jin L, et al. Sensitive determination of dopamine on poly(aminobenzoic acid) modified electrode and the application toward an experimental Parkinsonian animal model. Talanta 2001;55:329-36.

32. Zhao H, Zhang Y, Yuan Z. Study on the electrochemical behavior of dopamine with poly(sulfosalicylic acid) modified glassy carbon electrode. Anal Chim Acta 2001;441:117-22.

33. Gilbert O, Swamy BEK, Chandra U, Sherigara BS. Simultaneous detection of dopamine and ascorbic acid using polyglycine modified carbon paste electrode: a cyclic voltammetric study. J Electroanal Chem 2009;636:80-5.

34. Yao H, Sun Y, Lin X, Tang Y, Liu A, Li G, et al. Selective determination of epinephrine in the presence of ascorbic acid and uric acid by electrocatalytic oxidation at poly (eriochrome black T) film modified glassy carbon electrode. Anal Sci 2007;23:677-82.

35. Yao H, Sun Y, Lin X, Tang Y, Huang L. Electrochemical characterization of poly (eriochrome black T) modified glassy carbon electrode and its application to the simultaneous determination of dopamine, ascorbic acid, and uric acid. Electrochem Acta 2007;52:6165-71.

36. Liheng W, Xiaolei L, Yingtao D, Fei G, Qingxiang W. DNA biosensor based on a glassy carbon electrode modified with electropolymerizederiochrome black T. Microchim Acta 2014;181:155-62.

37. Gilbert O, Kumara Swamy BE, Chandra U, Sherigara BS, Electrocatalytic oxidation of dopamine and ascorbic acid at poly (eriochrome black-T) modified carbon paste electrode. Int J Electrochem Sci 2009;4:582-91.

38. Manjunatha JG. A new electrochemical sensor based on modified carbon nanotube-graphite mixture paste electrode for voltammetric determination of resorcinol. Asian J Pharm Clin Res 2017;10:295-300.

39. Laviron E. General expression of the linear potential sweep voltammogram in the case of diffusionless electrochemical systems. J Electroanal Chem 1979;101:19-28.

40. Bard AJ, Faulkner LR. Electrochemical methods fundamentals and applications. 2nd ed. Wiley; 2004. p. 236.

41. Yunhua W, Xiaobo J, Shengshui H. Studies on electrochemical oxidation of azithromycin and its interaction with bovine serum albumin. Bioelectrochem 2004;64:91-7.

42. Kianoush S, Ali AK, Mohammad J, Siavash B. Simultaneous determination of diclofenac and indomethacin using a sensitive 
electrochemical sensor based on multiwalled carbon nanotube and ionic liquid nanocomposite. J Appl Electrochem 2013;43:1217-24.

43. Majid A, Tahereh MG, Mohammad AZ. MWCNTs/Cu(OH) nanoparticles/IL nanocomposite modified glassy carbon electrode as a voltammetric sensor for determination of the non-steroidal anti-inflammatory drug diclofenac. Mat Sci Eng C 2012;32:1682-9.

44. Maryam G, Mohammad AK, Fatemeh K, Vinod KG, Mohsen K, Hassan B, et al. Square wave voltammetric determination of diclofenac in liquid phase using a novel ionic liquid multiwall carbon nanotubes paste electrode. J Mol Liq 2014;197:114-9.
45. Florica M, Monica I, Andriana R, Georgeta B, Joop S. Electrochemical determination of diclofenac sodium in aqueous solution on Cu-doped zeolite-expanded graphite-epoxy electrode. Electroanalysis 2010;22:2058-63.

46. Rogiyeh P, Mohammad RB. Silica nanoparticles modified carbon paste electrode as a voltammetric sensor for determination of diclofenac. Anal Bianal Chem Res 2017;4:261-8.

47. Shalauddin M, Shamima A, Samira B, Mohd SAK, Nahrizul AK, Wan JB. Immobilized copper ions on MWCNTS-chitosan thin film: enhanced amperometric sensor for electrochemical determination of diclofenac sodium in aqueous solution. Int J Hydrog Energy 2017:42:19951-60. 